\title{
Around the block
}

\author{
Y Philip Zhang
}

\section{A blocking patent can kill your business before it's off the ground.}

$$
\mathrm{O}_{\mathrm{ar}}^{\mathrm{natan}}
$$
ne of the most unpleasant surprises for any entrepreneur at a startup company is learning that a blocking patent threatens the commercial viability of their lead product. This could seriously jeopardize the company's ability to raise financing, its attractiveness to strategic partners and ultimately its overall viability as a business.

In this article, I provide a few pointers on how to avoid blocking patents in the first place and then go on to explain how to take evasive action if you are in the unfortunate position of sweating one out.

\section{First, avoid}

Officially, a blocking patent is one that is valid and enforceable and could prevent your potential product from coming to or perhaps staying on the market. In the United States and most industrialized countries, an actual or imminent patent infringement is grounds for government-sanctioned injunctions and monetary damages. Faced with hefty capital demands and long, perilous clinical trials, drug developers tend to avoid product candidates that present patent uncertainties and litigation risks, even if the drug satisfies unmet needs of patients. Concerns over patent infringement routinely interrupt and sometimes derail commercialization of drugs. Thus, freedom to operate (FTO) - the ability to develop and market a drug or device without infringing the valid and enforceable patent rights of others-should be high on your CEO agenda.

The starting point for securing FTO is to clearly identify the business space for your company. A blocking patent is relevant only if it affects your business. A first-level inquiry asks: What are the current and future (including

Y. Philip Zhang is cofounder and co-managing principal at Milstein Zhang \& Wu, Newton, Massachusetts, USA.

e-mail:philip.zhang@mzwiplaw.com potential) businesses that you are conducting and plan to conduct? A company in the drug discovery space faces different challenges than a company that is in the in vitro diagnostics space, for instance. A developer of new drugs typically must have a good understanding of discrete patent spaces around its drug targets and candidates in the pipeline. A company in the diagnostic or genetic testing business, on the other hand, may have to walk through the minefield of ever-increasingly patented biomarkers and immunoassays. A small-molecule drug developer generally is not too concerned with drug manufacturing. If you are developing recombinant proteins, however, manufacturing patents are plentiful and should be watched for.

Next, you should identify the technologies that are vital to your company, and this may be tougher than determining your business space. It is important for you to have a mental list of the critical and enabling technologies for successful commercialization of your products. You need to know what technologies are necessary to build your products and clarify which are your own innovations and which are other people's technology that you need access to. A developer of a single-molecule DNA-sequencing technology, for example, must evaluate FTO for its core sequencing platform but may also need to review reagents, optics, electronics and other enabling technologies. A bioethanol producer developing a new fermentation process may have to review its biomass pretreatment protocols and microorganism production steps as well as overall process integration.

Once you understand your business and technology space, you've paved the way for the next step: understanding the patent environment in which your business operates. The patent landscape affects your patent needs for protecting your business and your FTO. A common misconception is that if you have a patent on something then you are free to practice the technology disclosed or claimed in your patent. This is not true.
A patent grants its owner the right to exclude others from practicing the claimed invention without the owner's authorization, but it does not grant the owner a right to practice the claimed invention or technology disclosed in the patent. So even if you patented a technology, it doesn't mean that you necessarily can use it yourself because your patented technology could be dominated by another patent.

Thus, it is important early on to have a solid grasp of the patent environment surrounding key product candidates through rigorous patent search and review. The patent search and review process is preferably conducted by experienced legal counsel working closely with your project team. Scientists should resist the temptation to play patent lawyer. Understanding the science in a patent is important, but it's only the first step in understanding the impact of the patent, which is better done by, or with the guidance of, experienced counsel. A good patent lawyer is one who understands your business and the industry you operate in and can effectively communicate with your management and scientists. He or she understands the business ramifications of the patent issue at hand and helps you make the right judgment calls.

You and your counsel should map out the existing patent landscape along the entire commercialization path, even if your business plan is to seek exit before market entrance. If you find a patent that presents FTO risks, do not panic. The good thing is that not everything is patented (even though it might seem like it), and more often than not you will be able to find a path forward. Ideally, patent searches should cover both granted patents and published patent applications and additionally encompass all intended international markets for the product. Knowing where a patent is granted or pending helps with assessing its overall impact and affords you an early appreciation for the scope of your need for licensing, design-around options or patent challenge. 


\section{Box 1 Blocking patent? No}

Determining patent infringement involves a two-step analysis: first, construction of the claim to determine the coverage of a patent, and second, comparison of the alleged infringing composition, device or method with the construed claims. Thus, overcoming a patent means understanding its claim scope and designing the product outside such scope.

Consider the patent fight between Novartis Pharmaceuticals and Eon Labs manufacturing. Novartis has a patent on a drug formulation that claims a hydrosol, which includes solid particles of the drug compound and a stabilizer that maintains the size distribution of the particles. The claim further specifies the water solubility of the drug compound as well as the ratios of drug compound to water and drug compound to the stabilizer in the hydrosol.

Along comes Eon. It sells a drug product that includes the same drug compound but not in hydrosol form. Eon instead makes capsules that contain the drug compound dissolved in a small amount of ethanol. There is no water in these capsules, and the drug compound inside the capsule is completely dissolved in ethanol (not in particle form).

Novartis sued Eon for infringement, asserting that when Eon's capsule is ingested by a patient, an infringing hydrosol is formed when the capsule mixes with the aqueous environment of the patient's stomach. This unusual infringement theory did not survive summary judgment at the trial court (and on appeal) as Novartis' hydrosol claim was construed to be limited to a medicinal preparation consisting of a dispersion of solid particles in an aqueous colloidal solution prepared outside of the body, which Eon's capsules clearly are not ${ }^{1}$.

Another factor that may require some soul searching on your part is the risk profile of your company. Clearly articulating your risk tolerance can be difficult, but in many ways it shapes the appropriate approach to a patent problem. Your risk profile may change over time and is determined by a number of factors, including the business sector you operate in, the stage of your company, your financial situation, the liability exposure and the personalities of the management. The life science community in general and venture capital investors in particular are quite risk averse when it comes to patents and FTO. Because of the large capital need and lengthy and risky development process, investors do not like to deal with patent uncertainties and litigation threats. Technology and regulatory risks are already plentiful in biotech-you don't need anything more. Heightened patent risks could drive your board and the investors nuts.

A review of your FTO should not be a onetime occurrence, because a thorough search and review doesn't necessarily uncover all relevant patents. For one thing, patent applications are published 18 months after filing, so there is always a black box in the patent space. For another thing, your product design could change and your need for enabling technologies may evolve over time. A good grasp of the patent landscape affords you the ability to make adjustments along the product development path. In the life science sector, the point of each significant go or no-go decision is often a good time to revisit the patent situation. Competent counsel can guide you through the process. Ignorance is rarely a viable approachsophisticated investors and collaborators will conduct thorough due diligence on your patent position. It is better that you know your shortcomings before potential investors or partners point them out.

\section{Next, overcome}

If the worst happens and you do identify a potential blocking patent or patent application, it is critical to fully understand how it impacts your business. For example, does it affect the technology platform at the core level, a particular product composition, a manufacturing step or a specific use of a product? You and your patent counsel should understand the patent's legal status and the claim scope. Information on the patent (whether the claims are allowed, issued, on appeal, in interference, under reexamination or challenged in litigation) can be obtained by your counsel. Often a review of the patent file history is needed to fully grasp the scope of a patent and its real or potential weaknesses. Claims in different countries quite often are not identical; therefore, you should consider obtaining legal advice from a lawyer in each of the countries of interest.

In addition, you should gather background information about the patent owner as a prelude to a licensing effort or a preparation for challenge. Where the patent is licensed to a third party, information on the licensee could be valuable as well. They could become your competitor, collaborator, licensor, licensee or all of the above. Knowing their business situation, their financial clout, their technology and their patent needs can help you gain leverage and affect how you deal with the blocking patent and its owner. Patent ownership and licensing information may be obtained from appropriate databases, such as ones found at the US Patent and Trademark Office, the World Intellectual Property Organization and the US Securities Exchange Commission.

You'll then need to explore design-around options. Quite often, a blocking patent is relevant only because of one or two features of a candidate compound or device. When such features can be removed or modified without sacrificing the needed functionality, you might find a successful design-around solution. Working closely with your scientific team, an experienced lawyer can make significant contributions in identifying and finetuning successful design-around options.

In a hypothetical drug development scenario, a drug is approved by the US Food and Drug Administration for treating disease A. The owner of the drug has obtained patents on the drug compound, formulation and use of the compound to treat disease A. The drug, however, is now suspected to have potency against disease $\mathrm{B}$. The suspicion is further borne out by your preclinical studies.

In this scenario, FTO issues are clearly present due to the patent estate around the approved drug. These patents, however, might be limited to the approved drug compound itself and certain close derivatives. Some chemical compound patents suffer from insufficient enablement regarding distant derivatives and analogs. Analysis of the patents might reveal that all valid patent claims are tied to a certain core chemical scaffold or more commonly to certain specific functionalities on the core chemical scaffold. Working together, your scientists and patent counsel can design exploratory compound libraries that investigate the surrounding chemical space uncovered by the patent. Knowledge of the structure-activity relationship and the patent landscape is critical in successfully navigating the hit-to-lead evolution process. A good practice from a patent counsel's perspective is to fully grasp both technical and legal parameters while communicating effectively and working intimately with your project team. The objective should be to obtain a design-around solution that minimizes infringement risks and allows solid, fresh patent protection for the redesigned compound (Box $\mathbf{1}$ ).

When faced with a blocking patent, you should also explore the availability and cost of a 
patent license. Too often the project team drops a compound after the discovery that it is covered by a third-party patent. Licensing opportunities often are not carefully investigated and followed up, resulting in premature loss of good drug candidates. It is more desirable from efficiency and productivity perspectives that biotech startups become more open to licensing both at the receiving and giving ends.

You'll need your counsel to closely guide the licensing process, as many pitfalls exist that could entrap the unwary. A misstep could expose you to various risks, ranging from prematurely exposing your licensing needs to the patent owner to a loss of your right to later challenge the patent. It is generally a good idea to enter a confidentiality agreement before exchanging sensitive information and starting negotiations. You can also sometimes enter a joint privilege agreement if sensitive opinions or legal documents are shared with the other side.

Keep in mind, though, that the patent licensing process could be lengthy and exhaustive, and it can easily take months to complete. This means it's important to set a timetable and move forward accordingly. Your knowledge of the weaknesses of the desired patent estate and its holder could help steer the process favorably for you. In this regard, due diligence on the desired patent estate and its owner is must-do homework that should be completed before approaching the owner. Understanding the value of the license to you is important because the deal inevitably involves setting licensing fees and royalty rates. Experienced counsel might know the prevailing licensing rates and industry terms. Your ultimate objective in a licensing discussion is to fully explore the potential of a license in view of all other options available to you so that you can make a cogent business decision.

Though rarely enjoyable, sometimes the best approach is to simply challenge a blocking patent face on. It's preferable to have proactive patent challenges at favorable times and venues rather than mere reactive defenses. Well-planned and executed strategies for patent challenges often help realize the full commercial potential of your product.

Legal procedures vary from country to country, but some forms of patent validity challenge are available in all major jurisdictions. For example, Europe, Japan, China, Australia and Canada all have post-grant opposition or cancellation procedures. In the United States, the primary procedures for validity challenge at the US Patent and Trademark Office are ex parte and inter parte reexaminations. Currently, post-grant opposition is not available in the United States, but it is a part of most patent reform bills and could become available soon, as it's believed that some iteration of patent reform is likely to pass into law.

At any time after US patent issuance and before expiration, anyone may request reexamination on the grounds of a substantial new question of patentability based on printed prior art or patent references. A notable benefit is that the outcome of the ex parte reexamination does not have a binding effect on the requester, which means that you may raise the same basis of invalidity again in a pending or future patent litigation, essentially allowing you two bites at the apple. A potential downside, however, is that you do not have much direct participation in the proceedings, and the patent holder could steer that reexamination process to strengthen his or her patent. Inter parte reexamination, in contrast, allows more direct involvement, but the outcome has a binding effect on the requester. Heed your counsel's advice when formulating and implementing effective patent challenge strategies.

\section{Conclusions}

FTO is critical to life science startups. Not having it from the beginning of a venture is like a building without a foundation. A biotech startup is wise to craft and implement an appropriate patent strategy early on that steers it clear of and minimizes the impact of hostile patents. But should one appear, there are approaches to try in order to maneuver around it. Still, nothing can substitute for the commitment of the company and the teamwork of management, scientists and counsel.

1. Novartis Pharms. Corp. v. Eon Labs Mfg., Inc., $363 \mathrm{~F}$. 3d 1306 (Fed. Cir. 2004).

To discuss the contents of this article, join the Bioentrepreneur forum on Nature Network: http://network.nature.com/groups/bioentrepreneur/forum/topics 